\title{
Author's Reply: Management of Locally Advanced and Unresectable Small Bowel Neuroendocrine Tumours
}

\author{
Jonathan Koea ${ }^{1}$
}

Accepted: 15 March 2021 / Published online: 7 April 2021

(c) Société Internationale de Chirurgie 2021

Thank you for the opportunity to respond to the correspondence from Dr Clement and Dr Srirajaskanthan. They highlight the important point that total parenteral nutrition (TPN) has a role in the management of patients with unresectable neuroendocrine tumours (NETS) when a significant component of their symptoms are due to malabsorption or obstruction, either from advanced disease or consequent to significant enteric resection resulting in short gut syndrome. Working out the relative contribution of hormone excess, tumour bulk and location, short gut and partial luminal obstruction to symptomology in any given patient is not always straight forward as almost all are usually in play, but the relative contributions may vary, and may vary over time, in an individual patient. Overall experience with TPN in patients with advanced cancer has not demonstrated discernible clinical benefits [1], although the theoretical risk of promoting tumour growth with an unrestricted supply of nutritional substrate has not been not confirmed [2]. However, most of these investigations have been performed in patients with advanced adenocarcinoma and extrapolation of treatment principles and protocols from this patient group to patients with NETS is always fraught. Consequently, as Dr Clement and Dr Srirajaskanthan demonstrate, a small number of selected NET patients treated with TPN do derive benefit with improved quality of life and survival, usually within their own homes rather than institutions, and with acceptable complication rates in small contemporary series. Finding these patients is difficult and will involve careful assessment by all members of a NET focussed multidisciplinary team. As Hoda et al. [3] wrote in 2005- "we cannot conclude that any specific clinical factor can substitute for thoughtful, judicious assessment undertaken on a patient-by-patient basis". At least, in the world of NETS, not much has changed.

\section{References}

1. Chow R, Bruera E, Chiu L, Chow S, Chiu N, Lam H et al (2016) Enteral and parenteral nutrition in cancer patients: a systematic review and meta-analysis. Ann Palliative Med 5(1):30-41

2. Shaw JH, Humberstone DA, Douglas RG, Koea JB (1991) Leucine kinetics in patients with benign disease, non-weight-losing cancer, and cancer cachexia: studies at the whole body and tissue level and the response to nutritional support. Surgery 109(1):37-50

3. Hoda D, Jatoi A, Burnes J, Loprinzi C, Kelly D (2005) Should patients with advanced, incurable cancers ever be sent home with total parenteral nutrition? A single institution's 20-year experience. Cancer 103:863-868

Publisher's Note Springer Nature remains neutral with regard to jurisdictional claims in published maps and institutional affiliations.
Jonathan Koea

jonathan.koea@waitematadhb.govt.nz

1 North Shore Hospital, Takapuna, Auckland, New Zealand 